\title{
El episodio de Oliva-Gandía de 3-4 de noviembre de 1987: récord nacional de precipitación en 24 horas
}

\author{
Carlos Santos Burguete ${ }^{1}$ (csantosb@aemet.es) \\ Agustí Jansà Clar ${ }^{2}$ \\ Rafael Armengot Serrano 3 \\ Juan Pablo Simarro Grande (jsimarrog@aemet.es) $^{2}$ \\ Alfons Callado i Pallarés ${ }^{5}$ (acalladop@aemet.es) \\ Marc Compte Rovirola ${ }^{5}$ (mcompter@aemet.es)
}

\author{
${ }^{1}$ AEMET / Dirección de Producción e Infraestructuras \\ ${ }^{2}$ Universitat de les Illes Balears / Departamento de Física / Grupo de Meteorología \\ ${ }^{3}$ AEMET / Delegación Territorial en la Comunidad Valenciana (jubilado) \\ ${ }^{4}$ AEMET / Delegación Territorial en la Comunidad Valenciana \\ ${ }^{5}$ AEMET / Delegación Territorial en Cataluña
}

\begin{abstract}
RESUMEN
A las 8 horas del 4 de noviembre de 1987 en Oliva (València) se registraron oficialmente $817 \mathrm{~mm}$ de precipitación en 24 horas, un récord nacional que todavía no se ha batido. En Gandía, distante $9 \mathrm{~km}$, las mediciones de los días 3 y 4 a las 8 horas sumaron $864 \mathrm{~mm}$, caídos también en menos de 24 horas. Estos episodios de lluvia torrencial, con inundaciones repentinas y a veces catastróficas son relativamente frecuentes en el Mediterráneo, donde llueve menos días que en zonas atlánticas, pero con cantidades diarias a veces muy superiores. ¿Por qué son tan difíciles de predecir? Se describe en este estudio el episodio de Oliva-Gandía, la singularidad climatológica de la región, las predicciones realizadas con los modelos de la época (INM-LAM) y, como contraste, las predicciones reconstruidas con modelos (HARMONIE-AROME) y sistemas de predicción por conjuntos (SPC) actuales (AEMET- $\gamma$ SREPS). Este artículo es un resumen del capítulo Superrécord de Oliva de 3-4 de noviembre de 1987 del libro Física del caos en la predicción meteorológica (SANTos et al., 2018).
\end{abstract}

PALABRAS CLAVE: récord nacional de precipitación; influencia de la geografía física en la precipitación; sistemas de predicción por conjuntos; predicción probabilista; predicción operativa; fenómenos meteorológicos adversos.

\section{INTRODUCCIÓN}

Empezamos citando directamente un extracto del capítulo del libro referido: Los episodios de lluvia torrencial, con inundaciones repentinas, a veces catastróficas, son una constante en las zonas mediterráneas, no sólo españolas, sino también francesas, italianas, etc. Hasta hace relativamente poco este tipo de fenómenos, relacionados con la convección profunda y, por tanto, altamente caóticos, se consideraban sencillamente impredecibles. Nadie hubiera podido ser acusado de no avisar de una de tales catástrofes (para poder tomar medidas preventivas), porque se sabía que no se podían prever. Las 
grandes lluvias que condujeron a la rotura de la presa de Tous, el 20 de octubre de 1982, no obstante, fue un episodio que sacudió a la comunidad meteorológica y política a escala española y catalizó una serie de planes y medidas orientados en ir ganando predecibilidad para ese tipo de fenómenos. Seguramente estamos lejos, todavía, de una predicción cuantitativa segura o, cuando menos, de incertidumbre acotada, de extremos como los mencionados, pero sin duda se han dado pasos adelante muy importantes, por la mejora del conocimiento, la mejora de los modelos deterministas y, seguramente, también, por la posibilidad de delimitar cada vez mejor la incertidumbre, por el uso de los sistemas de predicción por conjuntos. Los modelos atmosféricos deterministas tienen gran dificultad en acertar simultáneamente la localización y la intensidad de la precipitación en fenómenos de esta magnitud. Con predicción por conjuntos, aunque no puedan darse con exactitud la intensidad ni la localización, pueden delimitarse zonas con abanicos de superación de umbrales, lo que puede aumentar notablemente la predecibilidad de estos eventos.

En la figura 1 podemos ver la ubicación de la zona (izquierda), un mapa de precipitaciones registradas en el día pluviométrico 3-4 de noviembre de 07 UTC a 07 UTC, e interpoladas espacialmente para tener un mapa de colores continuos así como, en el centro, una ampliación de la precipitación en la región. En la figura 1.b puede verse un grabado con otro caso histórico, el de Alzira del 04-11-1864.
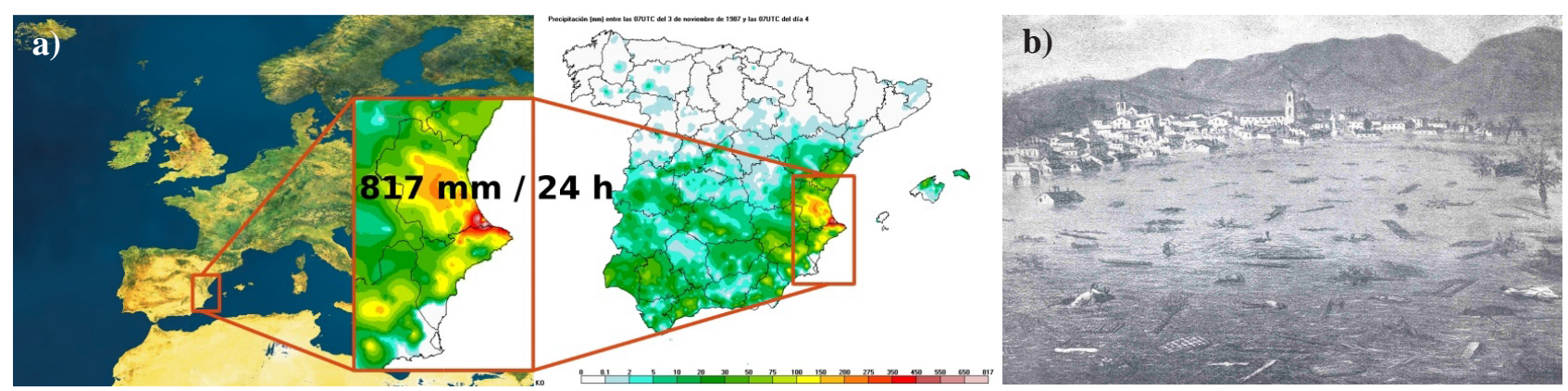

Figura 1. a) Récord nacional de precipitación en 24 h en Oliva-Gandía el 3-4 noviembre de 1987: ubicación de la región y precipitaciones registradas interpoladas espacialmente, con núcleos intensos en rojo en la zona.

b) Alzira durante la inundación del 4 de noviembre de 1864 (Grabado, CARreras y SARTHOU, 1910).

En su blog En el tiempo Ángel Rivera escribía una entrada en 2012 titulada ¿Por qué llueve tanto en La Marina Alta y en La Safor?, de la que seleccionamos un extracto: Nos hallamos pues en presencia de nubes eficientísimas en un entorno débil o moderadamente inestable que represadas entre las montañas de este extremo bético son como «esponjas» continuamente recargadas que «sueltan»la precipitación casi con la misma rapidez que la producen. En este trabajo se estudia, entre otros aspectos, el episodio en sí, desde el punto de vista de la predecibilidad: ¿podía haberse previsto una lluvia de copiosidad semejante?

\section{LA SINGULARIDAD PLUVIOMÉTRICA DE LA MARINA ALTA Y LA SAFOR}

En estas comarcas del sur del golfo de Valencia se produce el máximo pluviométrico del litoral mediterráneo peninsular. La articulación del relieve en valles orientados a los vientos del nordeste, húmedos y frecuentemente inestables, y la intrusión terrestre en el mar del entorno del cap de la Nau, facilitan episodios frecuentes de lluvias intensas. Estos episodios, cuando interaccionan nítidamente con el relieve, son captados cada vez mejor por los modelos numéricos; pero los episodios focalizados en la línea costera, en ocasiones torrenciales, aún poseen alta incertidumbre. 

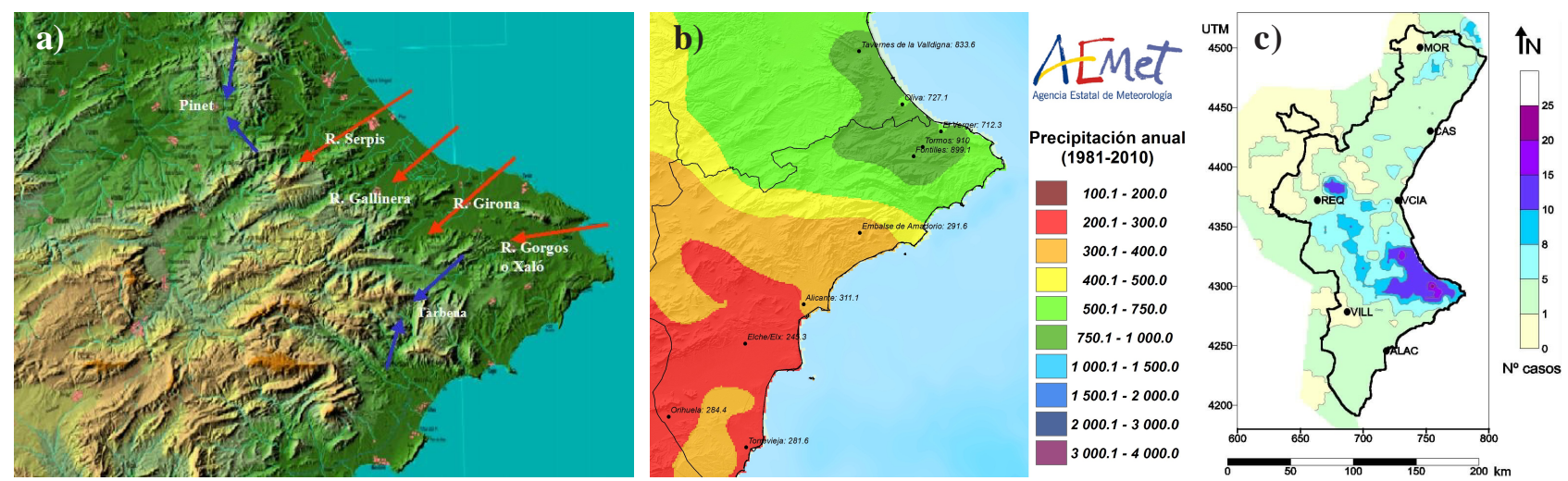

Figura 2. a) Mapa físico de la Safor, Marina Alta y zonas próximas. Se señalan los ríos principales, la incidencia de los vientos de gregal y algunas zonas de convergencia de sotavento (Jansà et al., 2018).

b) Precipitación media para el último periodo de referencia (AEMET). c) Frecuencia absoluta de casos de más de 100 mm/día en la Comunidad Valenciana en el periodo 1976-90 (ARMENGot, 2002).

Los cabos de Sant Antoni y la Nau marcan la salida de las cordilleras béticas al mar y suponen los límites de los golfos de València y Alicante, siendo este rasgo de intrusión terrestre en el mar una de las claves del extraordinario carácter pluviométrico de estas comarcas, vinculado a los vientos gregales y levantes mediterráneos (figura 2.a). Otra clave es la orientación noroeste-sureste del sistema Ibérico, cuyo extremo inferior alcanza la zona. El gradiente pluviométrico hacia el sur es uno de los mayores de la Península (figura 2.b). Además de unos valores medios elevadísimos, el número de días en que se registra lluvia intensa es hasta diez veces superior al de otras regiones (figura 2.c). Las causas fundamentales son:

- El carácter de intrusión terrestre en el mar, que supone un obstáculo y un disparador del ascenso de las circulaciones de capas bajas que discurren entre la península ibérica e Ibiza.

- Entramado de sierras con valles abiertos al este-nordeste, encarados a las circulaciones marítimas. Valles «en fondo de saco» que generan convergencia y ascenso forzado de estas circulaciones.

- Macizos montañosos que favorecen la penetración de las circulaciones marítimas por sus dos extremos para converger a sotavento, originando forzamientos orográficos y máximos de lluvia en la que, en primer análisis, sería zona de descensos de sotavento.

- Advecciones del nordeste (gregales), funcionales para la pluviometría en estas comarcas, son por su origen septentrional habitualmente más frías y discurren hacia el sur por un mar gradualmente más cálido, facilitando el carácter inestable de las mismas y con ello la rotura de las inversiones y el disparo de la inestabilidad.

- Ciclogénesis mediterráneas del mar de Palos y de Argelia, generadas por la interacción de las ramas ascendentes de vaguadas y depresiones aisladas de niveles altos (dana), con las montañas del Atlas marroquí $\mathrm{y}$ argelino.

Los modelos conceptuales que explican los diversos episodios estudiados pueden reducirse a cuatro grupos:

1. Precipitaciones convectivas marítimas asociadas a los máximos anuales de temperatura del agua del mar de final de verano. Suelen producirse en el litoral o en la franja costera. Aunque pueden desatarse con una sutil inestabilidad, puede ayudar el factor geográfico o una convección más potente. Son difíciles de predecir. 
2. Precipitaciones vinculadas a dana de otoño, posicionada en el entorno del Estrecho y desplazamiento lento hacia el NE, con circulación moderada en niveles medios-altos que no dificulte la organización de la convección y ciclogénesis en Alborán. El mar no acapara la convección, permitiendo estructuras intensas tierra adentro.

3. Precipitaciones por advección fría persistente, de invierno y primavera. Un caudal húmedo adecuado, no necesariamente inestable, con un gradiente de presión moderado a fuerte, conjugados con la acción orográfica de ascenso forzado y convergencias de sotavento.

4. Sistemas (o complejos) convectivos de mesoescala extremos. Dan lugar a las precipitaciones más extremas en menos de un día, aunque el número de casos es relativamente pequeño. Se conocen con seguridad dos casos desde 1950: 1-3 de octubre de 1957 (NuÑEZ, 2007) y 3-4 de noviembre de 1987, caso que nos ocupa.

Los modelos atmosféricos, en particular los no hidrostáticos, han permitido mejorar las predicciones de los tipos 2, 3 y, en parte, 4, aunque estamos todavía lejos de poder acertar en localización e intensidad simultáneamente.

Los diversos estudios sobre los periodos de retorno (tiempo estimado estadísticamente de la repetición de eventos extremos (WILKS, 2011) de precipitaciones intensas en la zona (RUIZ y NúÑEZ, 2011; WILKS, 2011) se basan principalmente en distribuciones de Gumbel y sufren limitaciones en el tamaño de las series de registros. Para episodios como este arrojan periodos de retorno milenarios, que no concuerdan con el hecho de que se hayan producido varios en un espacio bien inferior al siglo (véase figura 3).

a)

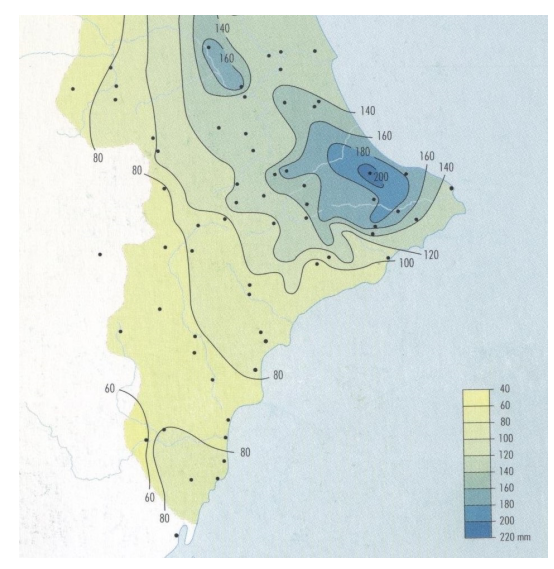

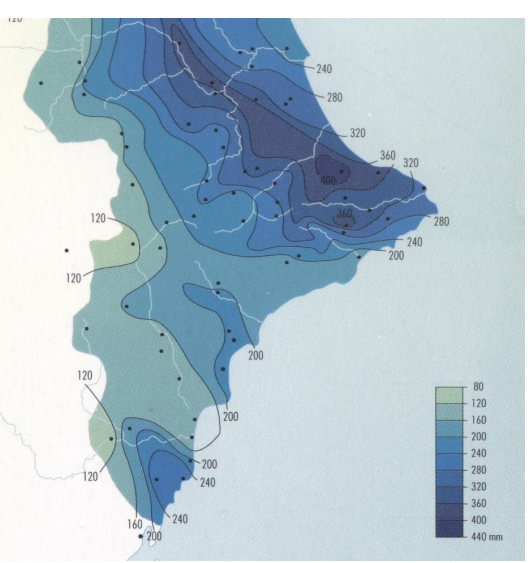

b)

Figura 3. Precipitación esperable para diferentes periodos de retorno en el sur de la Comunidad Valenciana; a) 5 años y b) 100 años (Cueva, 1994).

\section{EL EPISODIO}

Los días 3 y 4 de noviembre de 1987 estuvo lloviendo intensamente, durante muchas horas, en la comarca de La Safor, registrándose cantidades insólitas de precipitación en 24 horas, destacando la de Oliva, con $817 \mathrm{~mm}$ en el día pluviométrico 3-4 (de 8 a 8 horas), constituyendo el récord absoluto de precipitación en 24 h en España, una vez contrastado y confirmado por la Delegación Territorial de AEMET en València. El episodio completo, con unas treinta horas de duración, habría supuesto alrededor de $1000 \mathrm{~mm}$ (Riosalido et al., 1988). Se ha estudiado el episodio desde distintos puntos de vista, por diferentes autores. En la figura 4 pueden observarse algunos de los impactos en la ciudad de Oliva. 

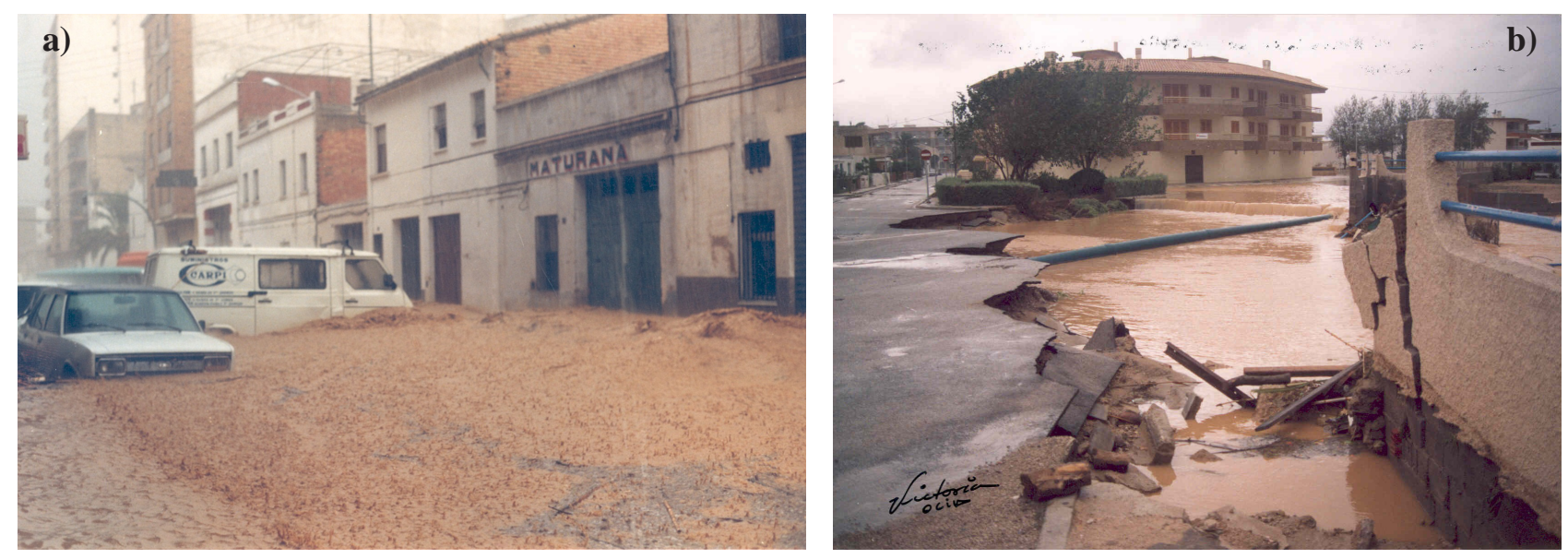

Figura 4. Impactos del episodio de Oliva, La Safor, València, el 3-4 de noviembre de 1987.

a) Inundación en Carretera de Pego esquina con Carrer Hermanos Benlliure, Oliva, La Safor, València, el 3 de noviembre de 1987. b) destrozos en la Vía de Ronda a la altura del Club Nautic.

Fotografías cedidas por el Ayuntamiento de Oliva (JANSÀ et al., 2018).

Se formaron sistemas convectivos de mesoescala (SCM), con notables desarrollos y cuyas zonas más activas se situaron repetidas veces, con zonas más activas semiestacionarias sobre el área de La Safor. En la figura 5.a podemos ver la imagen de satélite del episodio, con un enorme SCM sobre la zona; la 5.b muestra las precipitaciones registradas (RIOSALIDO et al., 1988). El episodio pluviométrico real tuvo dos grandes fases: una primera protagonizada por un potentísimo SCM, que afectó a la comarca de la Safor a lo largo de gran parte del día 3, con máximos en menos de 24 horas de 817 mm en Oliva y 864 en Gandía. Y una segunda que fue tomando fuerza a partir de la tarde del día 3 y no cesó hasta la madrugada del día 5, apoyándose marcadamente en la orografía y afectando especialmente a comarcas interiores de la cuenca del Júcar, con máximos también altísimos. Las precipitaciones se produjeron en una zona de frontera entre un entorno altamente inestable al este, con valores de CAPE altos en amplias zonas del Mediterráneo, con máximos superiores a $2000 \mathrm{~J} / \mathrm{kg}$ y una zona estable en el interior. La Comunidad Valenciana quedó inmersa en dicha frontera. La configuración del viento era del noreste en niveles bajos, girando hasta el suroeste en niveles altos. Esta configuración es típica en situaciones de precipitaciones intensas en la zona, facilitando la organización de la convección y su carácter cuasiestacionario durante un periodo prolongado.

a)

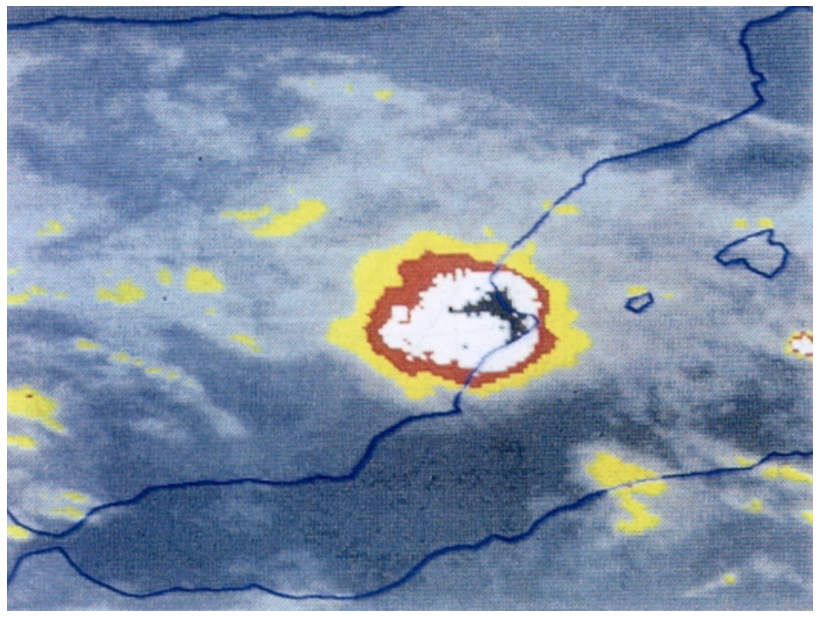

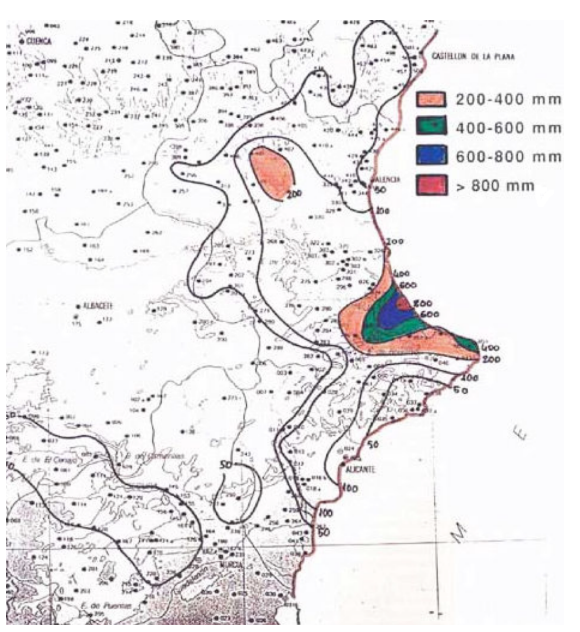

b)

Figura 5. a) Imagen de satélite infrarroja del día 4 de noviembre de 1987, a las 05:30 UTC, con color realzado; el amarillo corresponde a una temperatura de radiación en el intervalo $[-42,-32]^{\circ} \mathrm{C}$, rojo $[-54,-42]{ }^{\circ} \mathrm{C}$, blanco $[-64,-54]{ }^{\circ} \mathrm{C}$ y negro por debajo de $-64{ }^{\circ} \mathrm{C}$.

b) mapa de precipitación recogida en el día pluviométrico 3-4 de noviembre de 1987.

El máximo de más de $800 \mathrm{~mm}$ está enmarcado en una zona relativamente extensa en la que se superan los $400 \mathrm{~mm}$ (Riosalido et al., 1988). 


\section{CONSISTENCIA CON EL MODELO CONCEPTUAL}

La figura 6.a muestra el modelo conceptual general que explica estas situaciones: la depresión C (tanto borrasca convencional como depresión aislada en niveles altos o dana), configura el escenario sinóptico, la depresión mesoescalar B orienta el flujo alimentador hacia la zona y el área A es donde se registran las precipitaciones intensas. Se dieron condiciones apropiadas en niveles altos para un escenario de convección sobre la región de Valencia. En niveles bajos, el análisis manual (figura 6.b) revela la presencia de una pequeña baja centrada entre las costas valencianas y las africanas, ideal para organizar un intenso flujo cálido y húmedo, actuando como factor de inestabilización.

a)

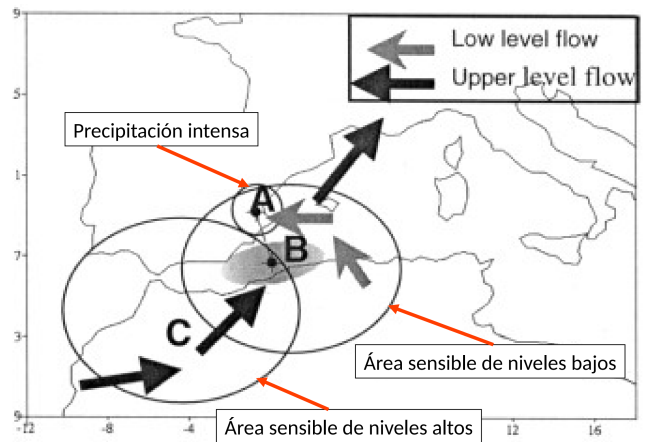

b)

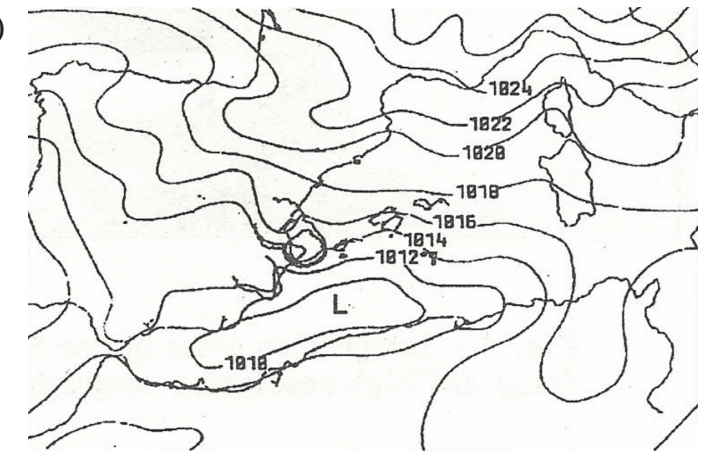

Figura 6. a) Modelo conceptual general que explica el episodio. b) Análisis manual de presión a nivel del mar, día 4 de noviembre de 1987, a las 00 UTC, espaciado $2 \mathrm{hPa}$. La línea festoneada indica la situación del principal sistema convectivo de mesoescala (SCM). Se observa una pequeña baja entre las costas valencianas y las africanas, factor clave en el episodio (véase texto).

\section{MODELOS AÑOS 90 INM/LAM}

En el entonces Instituto Nacional de Meteorología (actual AEMET), se hicieron experimentos numéricos entre 1989 y 1991 con el modelo INM/LAM entonces disponible, de área limitada del Centro Europeo de Predicción a Plazo Medio (BurRIDge y Haseler, 1979), con una resolución habitual de $0,91^{\circ}$. Probando con $0,455^{\circ}$, las predicciones daban buenas indicaciones sobre el tipo de situación meteorológica y precipitación generada (véanse las figuras 7.a y 7.b), con un máximo de más de $100 \mathrm{~mm}$, localizado bastante cerca del máximo observado. La relativamente buena predecibilidad del caso podría venir favorecida por la importancia de los efectos orográficos, que no tienen, en sí, incertidumbre. La orografía africana (Atlas) contribuye decisivamente a la generación de la depresión marítima y, con ello, a la organización y localización del flujo cálido y húmedo, alimentador de la lluvia fuerte. El relieve pirenaico contribuye, también, a la organización de ese flujo, mientras que el relieve interior a la zona de La Safor es un factor clave de escala menor, forzando ascenso del aire mediterráneo inestable incidente. Las figuras 7.c y 7.d muestran el impacto en la situación meteorológica en niveles bajos y la precipitación simulada cuando toda la orografía es fuertemente reducida, aplicando un factor 0,3 a la altitud media de toda la región. La depresión marítima se debilita claramente, con lo que también se desorganiza y debilita el flujo de aire mediterráneo y el máximo de lluvia pierde casi la mitad de su valor, en relación al experimento de control, además de sufrir cierto desplazamiento.

En otro estudio (ROMERo et al., 2000) de casos mediterráneos importantes, se utilizó el modelo MM5 (GRELl et al., 1994) con una resolución de 20 km (figura 8). La precipitación total acumulada se muestra en intervalos de $30 \mathrm{~mm}$, en gris las áreas afectadas por precipitación persistente. La presión a nivel del mar se acompaña con la convergencia en $925 \mathrm{hPa}$ y la velocidad del viento en aquellas áreas donde es significativo en tonos grises. El modelo es capaz de simular el sistema convectivo longevo y cuasiestacionario, así como la influencia relevante de los dos factores físicos considerados (orografía africana y liberación de calor latente) para la configuración mesoescalar de la circulación en niveles bajos responsable de alimentar y focalizar 
a)

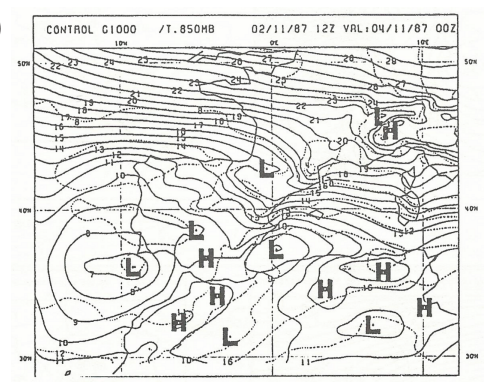

c)

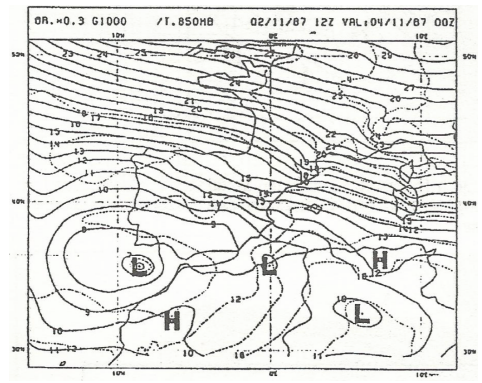

b)

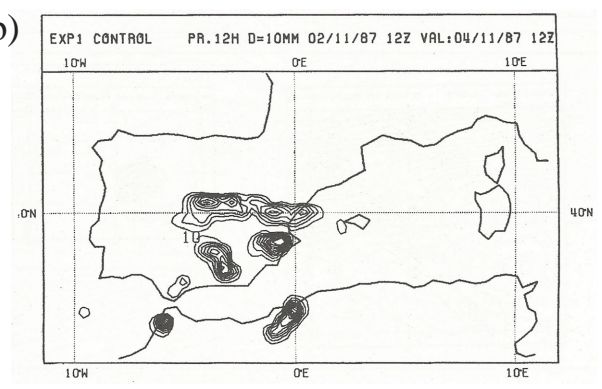

d)

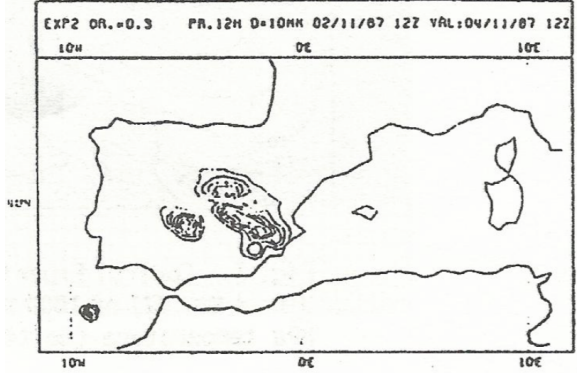

Figura 7. Simulación del episodio con el modelo LAM/INM a $0,455^{\circ}$ de resolución (a,b) y con orografía reducida en altitud $(\times 0,3, \mathrm{c}, \mathrm{d})(\mathrm{J}$ ANSÀ et al., 1991). a,c) Presión al nivel del mar y temperatura en $850 \mathrm{hPa}$.

b,d) precipitación de 00 a 12 UTC del día 4-11-1987.

a)

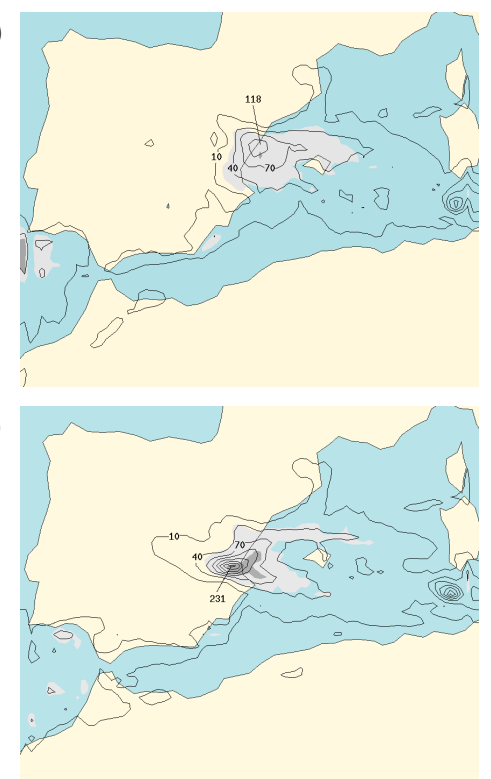

b)

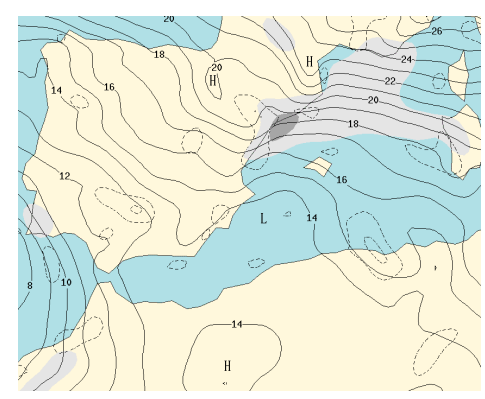

d)

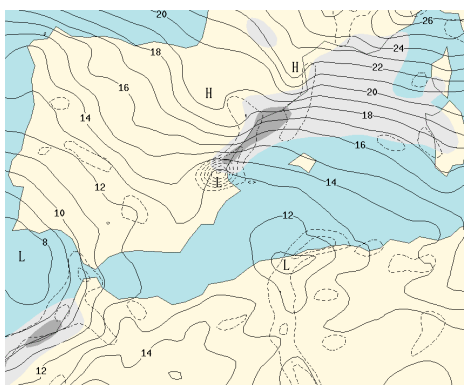

Figura 8. Estudio del episodio en RoMEro et al., 2000, con integraciones del modelo MM5 (Grell et al., 1994) a $20 \mathrm{~km}$ de resolución, simulación completa (c,d) y sin orografía africana ni intercambios de calor latente en procesos nubosos $(\mathrm{a}, \mathrm{b})$, precipitación acumulada $(\mathrm{a}, \mathrm{c})$ y circulación en niveles bajos $(\mathrm{b}, \mathrm{d})$. Véase texto.

dicho sistema convectivo. En cuanto a la situación meteorológica en niveles bajos, está claro que hay una depresión, relativamente poco intensa, centrada entre la costa argelina y la valenciana, dando lugar a un flujo cálido y húmedo sobre el Mediterráneo, apuntado a La Safor. El máximo de precipitación simulado por el MM5 está, como el señalado por el LAM/INM, próximo al máximo observado. En el caso del MM5 se superan los 200 mm entre las 00 UTC del día 3 y las 12 UTC del día 4. La congruencia a grandes rasgos, a escala intermedia, entre dos modelos bien distintos, partiendo de condiciones iniciales también distintas indica que, a esa escala, hay una buena predecibilidad. La comparación entre resultados sería como haber usado un sistema minimalista de predicción por conjuntos, de solo dos miembros (estilo SPC del hombre pobre, Ebert, 2001; Quiby y Denhard, 2003). 


\section{MODELO 2017 HARMONIE-AROME}

Damos un salto de unos 30 años para comparar los modelos de la época con la actualidad. Mostramos en esta sección simulaciones del episodio con el modelo HARMONIE-AROME (BENGTSSON et al., 2017), utilizando el reanálisis ERA-Interim (DeE et al., 2011) como condiciones iniciales y de contorno.

ERA-Interim es una base de datos del ECMWF de reanálisis atmosféricos desde 1979 hasta la actualidad, mejorado con respecto a ERA-40 (UPPALA et al., 2005). El salto de resolución del ERA-Interim (80 km) al HARMONIE-AROME $(2,5 \mathrm{~km})$ es grande. No obstante, aunque reduce la calidad de la simulación inevitablemente, no se aprecian problemas numéricos en las zonas del contorno y se recogen resultados consistentes. Utilizando ERA-Interim directamente, un somero análisis de la génesis de la perturbación que produjo las precipitaciones torrenciales indica que la dana tuvo un largo recorrido, estando definida al menos desde el día 25 de octubre, cruzando el Atlántico Norte, y sufriendo una deformación al llegar a Europa, elongándose y perdiendo durante unos días su forma circular. En este proceso se separaba de la circulación del frente polar, y queda confinada en latitudes más bajas, bloqueada por sendas dorsales al oeste y este, recuperando su forma circular. La dorsal al este tomaba fuerza y se extendía hacia el noroeste, situándose el día 03-11-1987 al norte de la baja, que en ese momento se centraba en el golfo de Cádiz.

a)

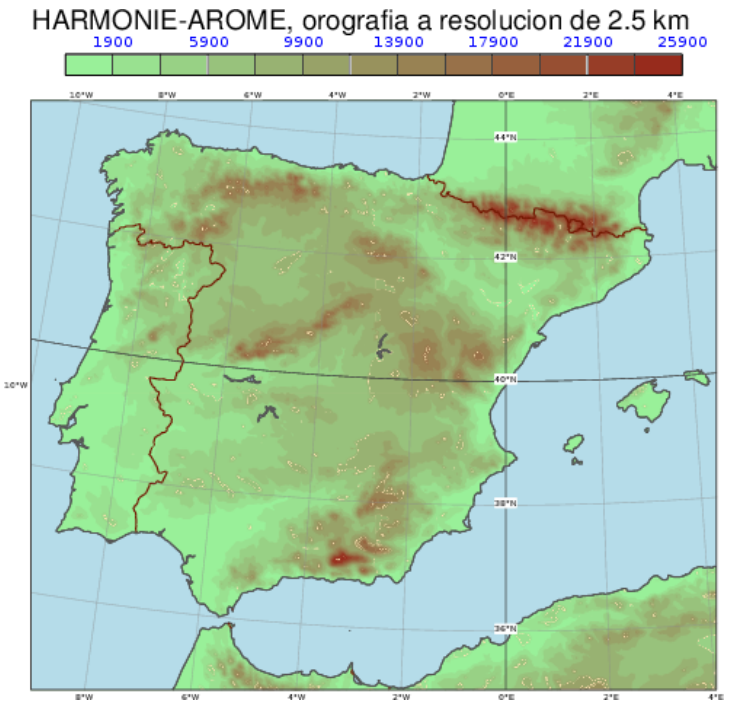

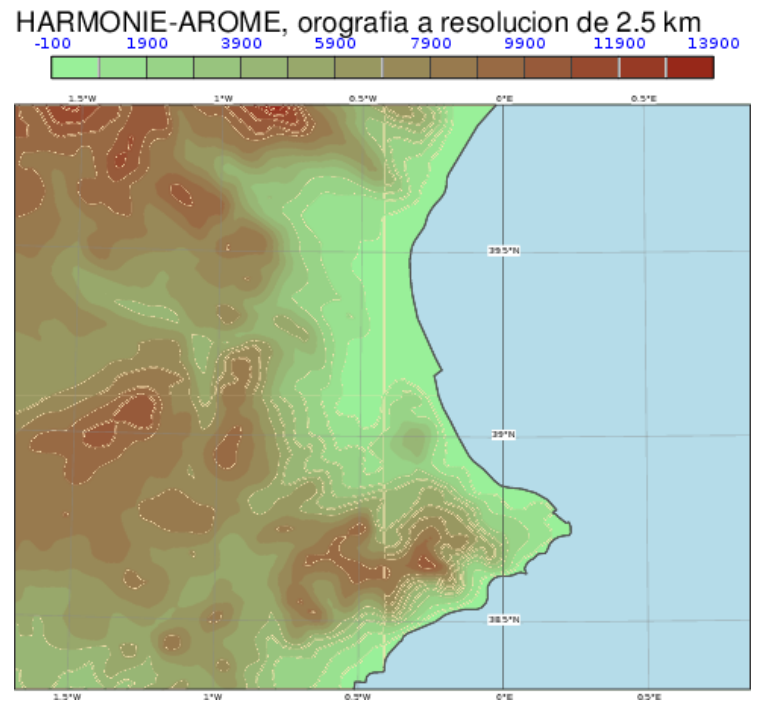

Figura 9. Orografía del modelo HARMONIE-AROME de AEMET a 2,5 km. a) Península y Baleares.

b) Detalle del sur de la Comunidad Valenciana.

El modelo HARMONIE-AROME es un modelo no hidrostático de mesoescala que permite simular explícitamente la convección. El área de integración usada está centrada en la península ibérica, con 2,5 km de distancia entre puntos de malla y 65 niveles en la vertical. Este modelo se usa actualmente (2018) de forma operativa en AEMET, conjuntamente con el modelo global HRES del ECMWF (GuTIÉRREZ y GHELLI, 2018).

Se han hecho dos simulaciones HARMONIE-AROME independientes, la primera comienza el 03-11-1987 a las 00 UTC y la segunda el 04-11-1987 a las 00 UTC, ambas con un alcance de 36 horas, cubriendo conjuntamente desde las 00 UTC del día 3 hasta las 12 UTC del día 5. Simular la convección profunda de forma explícita (no como los modelos hidrostáticos que la parametrizan), así como basarse en una orografía de tan alta resolución (figura 9), produce campos de precipitación más realistas, con máximos más cercanos a los observados, con una representación relativamente buena de los vientos locales y la influencia de los accidentes geográficos sobre la configuración de estos, sobre todo en niveles bajos. Se reproducen consistentemente los ingredientes meteorológicos del episodio (no mostrado). 
a)

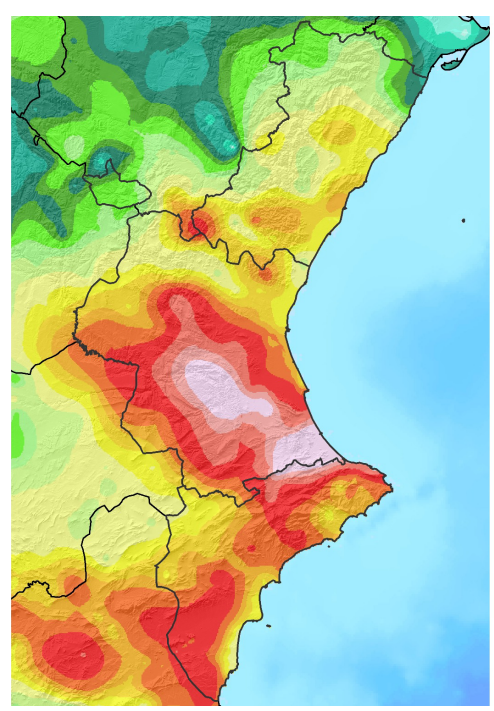

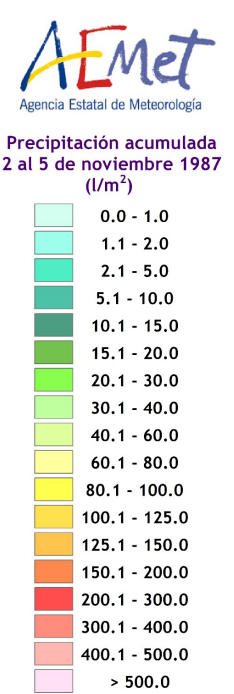

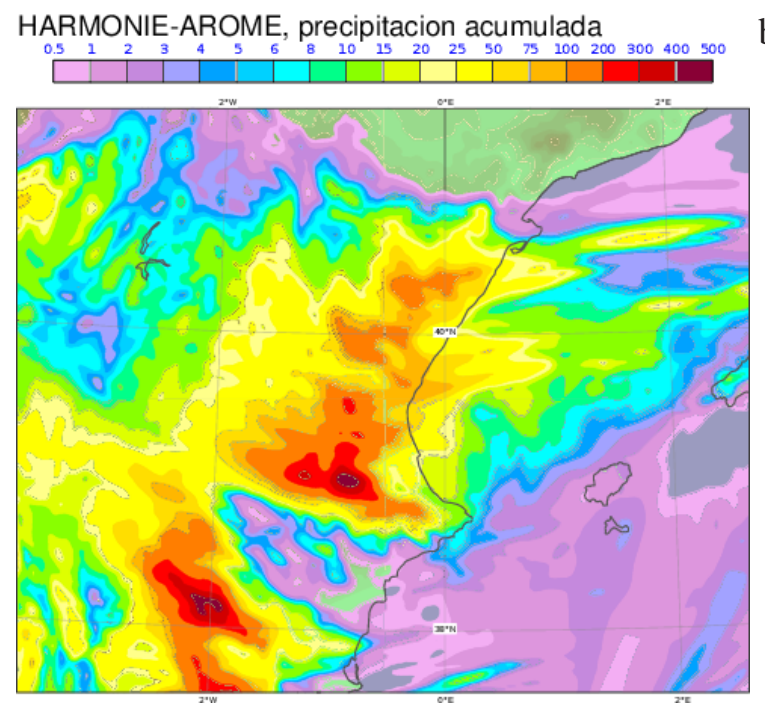

b)

Figura 10. Comparación entre precipitación observada y prevista. a) Precipitación registrada (observación).

b) Precipitación prevista (predicción).

Comparando el análisis del campo de precipitación observado (figura 10.a) y el simulado (10.b) las similitudes son notables, tanto en la localización como en las magnitudes, con algunas diferencias importantes. La integración no consigue representar el SCM de la primera fase del episodio en La Safor, reflejando solo una zona de precipitación poco extensa en la madrugada y mañana del día 3, que nace en el interior sur de la comarca de la Safor y se traslada posteriormente hacia el oeste, pero que no afecta al litoral ni tiene una magnitud muy destacable. Sin embargo, los resultados de la segunda fase muestran una calidad muy superior, simulando bien la enorme magnitud y la localización de las principales zonas de precipitación. En cuanto a la evolución temporal de la precipitación, la simulación aumenta la actividad paulatinamente, desde la madrugada del día 3 hasta un máximo por la tarde del día 4, con máximos relativos; disminuye paulatinamente desde entonces hasta cesar casi por completo al final de la integración, el día 5 a mediodía (figura 11).

Puede concluirse que los avances de la modelización numérica son notables, pero persisten algunas limitaciones e incertidumbres. Con respecto a INM/LAM, mejora la predecibilidad del máximo inducido orográficamente, pero no tanto la del máximo costero. De producirse un caso muy similar, una simulación como esta sería una importantísima guía para la predicción y vigilancia de la segunda parte del episodio, marcadamente sinóptica y muy apoyada en la orografía. Por el contrario, nos mantiene en la incertidumbre respecto a la posibilidad de haber predicho con antelación el gran SCM que afectó a la comarca de La Safor y que inició el episodio.

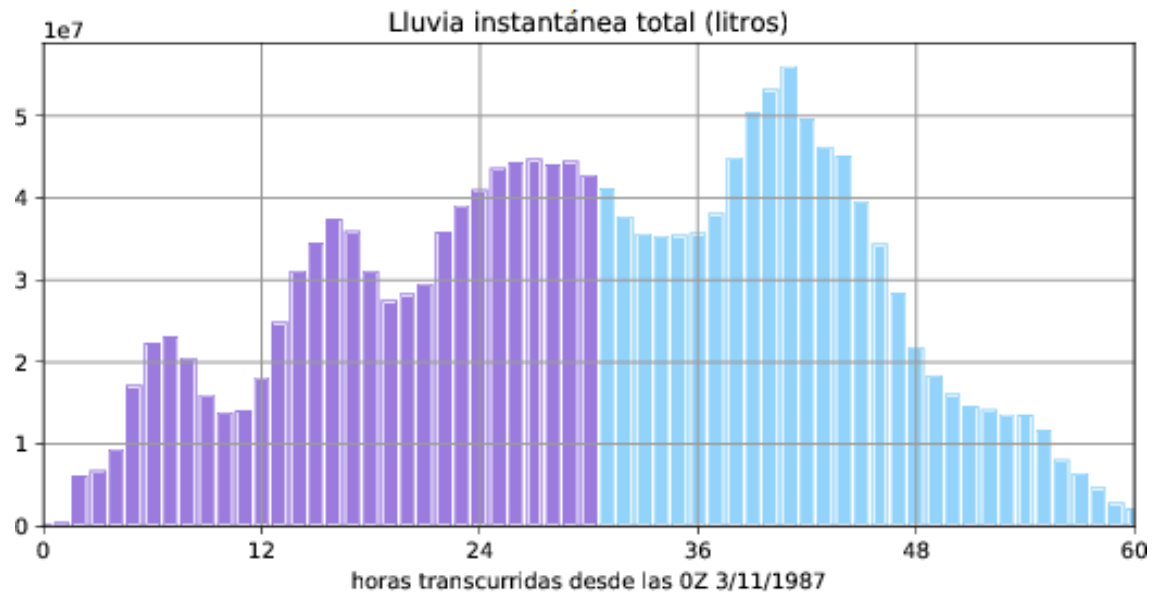

Figura 11. Intensidad de precipitación prevista. 


\section{SISTEMA DE PREDICCIÓN POR CONJUNTOS 2017 AEMET- $\gamma$ SREPS}

Se simuló el episodio con el SPC de alta resolución AEMET- $\gamma$ SREPS operativo en AEMET a 2,5 km (CAllado et al., 2018) con la idea de ahondar más, desde el punto de vista de la predecibilidad del mismo y de cómo acotar las incertidumbres asociadas al episodio, en relación con la pregunta ¿podría haberse previsto una lluvia de copiosidad semejante con los SPC actuales de alta resolución?

El AEMET- $\gamma$ SREPS operativo funciona con 20 miembros, cruzando las 5 condiciones iniciales y de contorno: ECMWF/IFS, NCEP/GFS, MétéoFrance/ARPÈGE, JMA/GSM y CMC/GEM; con 4 modelos: HARMONIE-AROME (HIRLAM), ALARO (ALADIN), WRF-ARW (NCAR) y NMMB (NCEP). Así, la predecibilidad sinóptica viene más marcada por las 5 condiciones de contorno, mientras que la predecibilidad mesoescalar/convectiva, es más explorada por los 4 modelos que, además, por ser convection-permitting pueden organizar la convección de forma natural e incluso simular un SCM.

En este estudio se emplea un AEMET- $\gamma$ SREPS usando reanálisis para fines de repredicción, que llamaremos abreviadamente RayS, con 12 miembros cruzando los 4 modelos con 3 condiciones de contorno de tres reanálisis: ERA-Interim (ECMWF), CFSR (NOAA-NCEP) y JRA-55 (JMA). Además, a las limitaciones

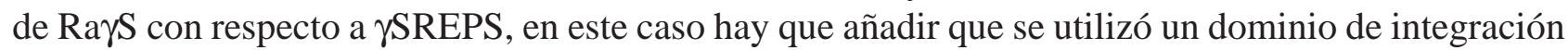
especialmente pequeño. Se simuló el episodio desde el día 2 a las 12 UTC hasta el día 5 a las 12 UTC, 72 horas, algo excepcional tratándose de un SPC convection-permitting. En la cadena operativa, se traduciría en que la tarde del día 2 estarían los productos disponibles para hacer las predicciones de los dos días siguientes.

Debemos recordar que, probablemente, por limitaciones de observaciones y análisis para las condiciones iniciales, tendencia conservadora de los modelos, con difusiones o filtros en la dinámica, limitaciones en las salidas de las parametrizaciones de la física, así como el propio diseño en la construcción de los SPC e, incluso, también la propia naturaleza incierta del fenómeno meteorológico, los eventos extremos aparecen normalmente en la cola de la distribución (en la cola de la PDF) de un SPC. En otras palabras, normalmente solo unos pocos miembros del SPC ven el fenómeno extremo en su magnitud real. Este hecho condiciona los productos de un SPC que escruta un predictor cuando sospecha la posibilidad de un fenómeno meteorológico adverso y/o extremo. Por tanto, prestaremos atención a esos productos de un SPC que nos proporcionen más información sobre la posibilidad del fenómeno extremo de acumulación cuantiosa de precipitación.

En la figura 12 podemos ver resultados calculados para el periodo de 60 horas desde el día 3 a las 00 UTC hasta el día 5 a las 12 UTC. El máximo de precipitación acumulada (12.a), en cada punto de malla, de todos los 12 miembros de RA $\gamma \mathrm{S}$. Este producto $\mathrm{NO}$ es una predicción de ningún miembro y no tiene sentido estricto meteorológico por falta de consistencia, pero es un primer aviso para un predictor de que algo crítico puede suceder. Observamos una amplia zona con acumulaciones superiores a los $250 \mathrm{~mm}$ y, dentro de esta, otra importante de más de $500 \mathrm{~m}$ e, incluso, un par de máximos de más de $800 \mathrm{~mm}$. Mirando la mediana, en cada punto de malla, de los 3 miembros con más lluvia (12.b), advertimos dos cosas: que la precipitación disminuye mucho (¿incertidumbre espacial entre miembros?) y que se dibujan mejor máximos no tan lejanos a los observados, tanto los de Oliva y Gandía como otros; probablemente es debido a que son los 3 miembros con más precipitación los que mejor simulan la evolución del SCM, y solo el miembro 3 (en rojo) es capaz de ver alguna acumulación importante en la misma línea de la costa. Los mapas de probabilidad de precipitación acumulada por encima de $200 \mathrm{~mm}$ (12.c), con el ploteo adicional de las isolíneas de los miembros individuales, nos muestran con probabilidades del 40-70\% las localizaciones de los máximos descritos con la mediana de los 3 miembros. Se advierte, con las isolíneas de cada miembro, que en las zonas con una orografía más marcada hay menos incertidumbre entre ellos, pero al alejarnos de ella aumenta. En general, la incertidumbre más grande entre miembros es en la extensión de las precipitaciones acumuladas. Con probabilidad por encima de $400 \mathrm{~mm}$ (12.d), nos damos cuenta de que solo 2 miembros, el 3 rojo y el 11 lila ven tales acumulaciones: los únicos capaces de reproducir el SCM en la primera fase del episodio. 
a) AccPcp max

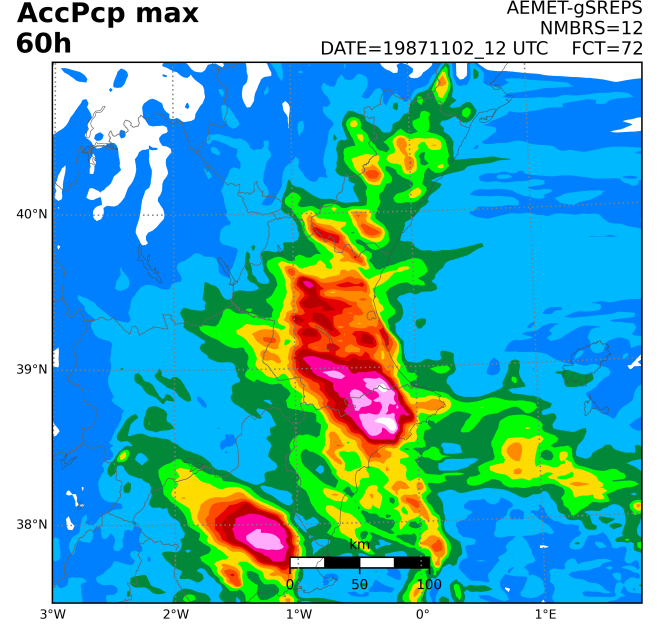

c) AccPcp prob $>=200 \mathrm{~mm} / 60 \mathrm{~h}$ AEMET-GSREPS AccPcp mbrs DATE $=19871102 \_12$ UTC $\quad$ FCT $=72$
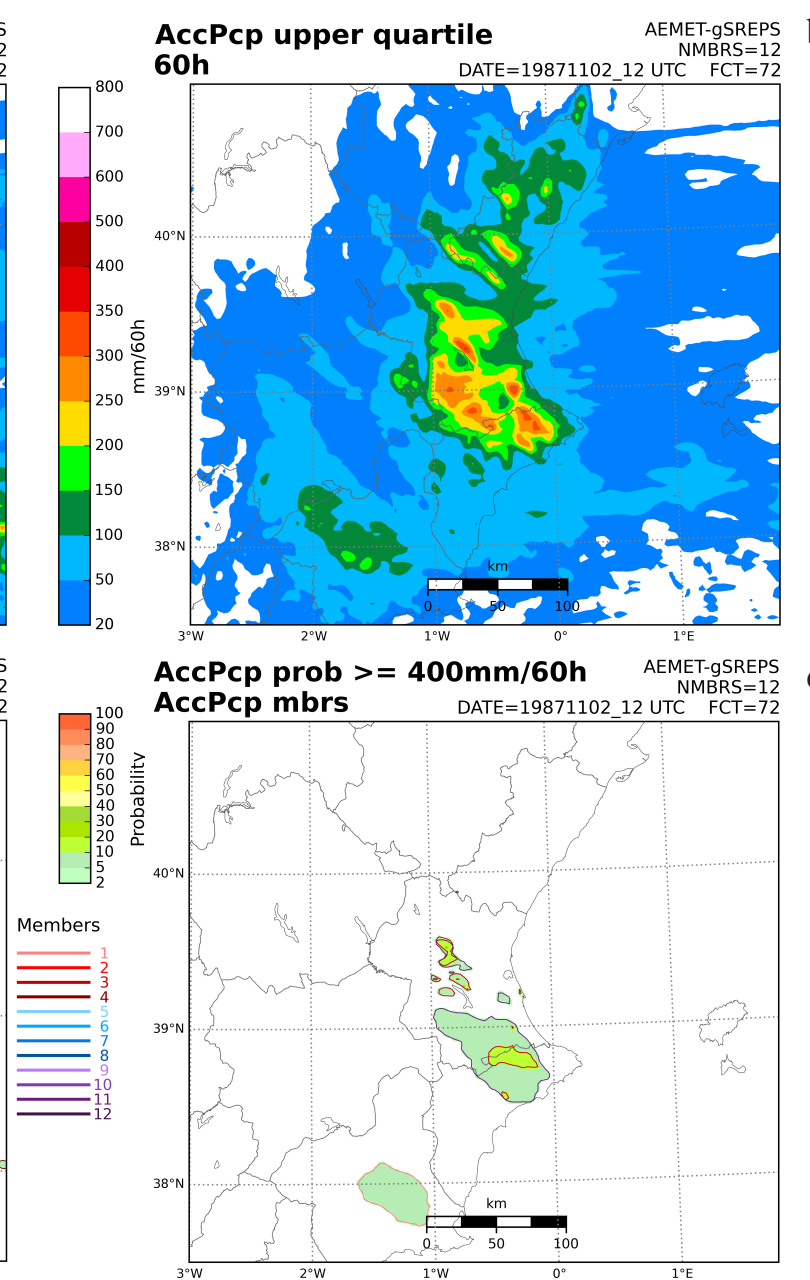

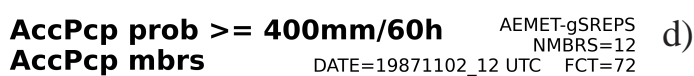

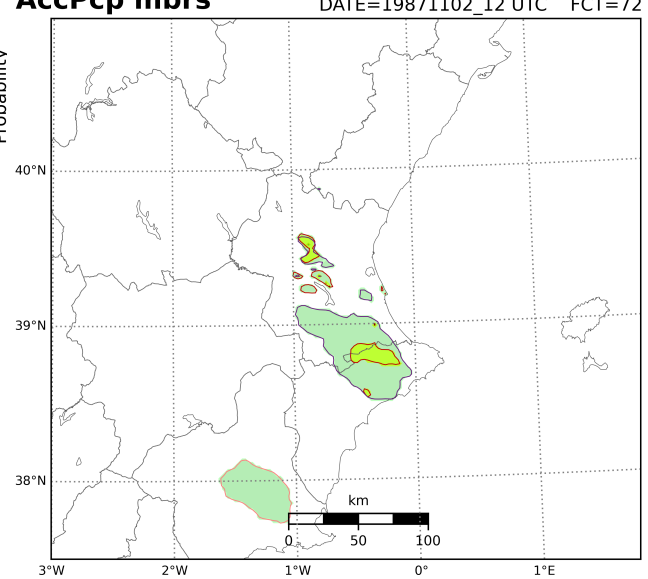

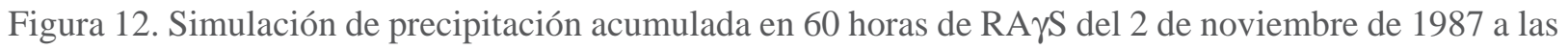
12 UTC para el episodio Oliva-Gandía desde el día 3 hasta el día 5 al mediodía. a) Máxima precipitación acumulada entre los 12 miembros. b) Mediana de la precipitación de los 3 miembros con más precipitación acumulada. (c,d) probabilidad de precipitación superior a $200 \mathrm{~mm}(400 \mathrm{~mm})$ y contorneo de la isolínea de

$200 \mathrm{~mm}(400 \mathrm{~mm})$ para cada uno de los 12 miembros. Se consignan localizaciones y valores de las precipitaciones observados en los días 3 y 4 pluviométricos, así como localización y valor máximo de precipitación del HARMONIE-AROME determinista (fuente: AEMET).

Realizando un estudio similar sobre las dos etapas del estudio por separado (no mostrado), se demuestra que

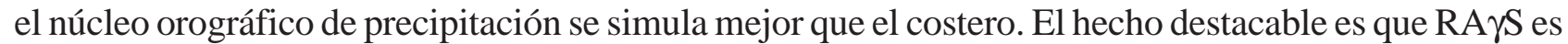
capaz de ver el costero, aunque subestime su intensidad. Podemos concluir que el SPC de mesoescala puede ayudar dando una indicación aproximada de probabilidades de un evento de precipitación extrema, aunque los detalles no se perfilan de forma determinista.

Para conocer la utilidad potencial del SPC de mesoescala en la predicción operativa se ha supuesto la situación en la que fuéramos predictores el día 2 de noviembre de 1987 por la tarde y dispusiéramos de la simulación del $\gamma$ SREPS, prediciendo los avisos meteorológicos de precipitaciones acumuladas en 12 horas, para el día siguiente día 3 y para el pasado mañana día 4, emulando tal como se pondrían hoy en día (2018) desde el Sistema Nacional de Predicción de AEMET. Los tres niveles de avisos por precipitación acumulada en 12 horas en todas las zonas son de amarillo, naranja y rojo por encima de 60, 100 y $180 \mathrm{~mm}$ respectivamente. Los tres niveles son adjetivados con probabilidades en 3 horquillas: 10-40\%, 40-70\% y más de $70 \%$. Nos fijaremos más explícitamente en las zonas de avisos donde se observaron los máximos de precipitación, sin fijarnos en Castellón. 
En la figura 13 vemos la simulación del RA $\gamma \mathrm{S}$ del 2 de noviembre de 1987 a las 12 UTC para la primera fase del episodio Oliva-Gandía de precipitación acumulada en 4 periodos de 12 horas durante los días 3 y 4 . a,d,g,j (columna izquierda) muestran el miembro que da el máximo de precipitación en cada punto de malla; b,e,h,k (columna central) la probabilidad de superar los 60 o $100 \mathrm{~mm}$ en cada punto de malla. Nótese que en los dos primeros periodos (día 3) el límite de la probabilidad de precipitación acumulada es 60 mm y en los siguientes es de $100 \mathrm{~mm}$. c,f,i,l (columna derecha) muestran el mapa de avisos en el Sistema Integral de Gestión de Avisos (SIGA) de AEMET (fuente: AEMET). Se consignan las zonas de aviso (arriba derecha) para facilitar la compresión del texto. Se recorren las cuatro fases:

1. Atendiendo a las probabilidades, y que solo dos miembros llegan al umbral de aviso, tomamos la decisión conservadora de un aviso amarillo con probabilidad baja para empezar un episodio más largo, que va a continuar en los siguientes periodos de avisos de 12 horas. Pero, alertamos a nuestros compañeros responsables de las tareas de vigilancia meteorológica de que estén atentos a ese inicio del episodio debido a que RA $\gamma \mathrm{S}$ apunta máximos de lluvia de 120-180 mm extensos e incluso un máximo localizado de 180-250 mm y que anoten que este inicio del episodio muestra una gran incertidumbre espacial.

2. El episodio va a más: nos damos cuenta de que tres cuartas partes de los miembros superan el umbral de aviso amarillo y que persiste una gran incertidumbre espacial, lo que penaliza a las probabilidades en el ploteo, quedando bajas. Volvemos a tomar una decisión cauta por la gran incertidumbre: aumentamos la probabilidad a moderada (40-70 \%) en las zonas de aviso amarillo y las extendemos a más zonas. Recomendamos al responsable de la vigilancia meteorológica tener una especial atención al seguimiento del evento precipitante debido a que se simulan dos zonas grandes, con baja probabilidad (10-40\%), de precipitaciones máximas de 180-250 mm y aparece un posible máximo en el litoral norte de Alicante de 250-300 mm.

3. Interpretamos fácilmente con la simulación del RałS que el episodio sigue recrudeciéndose, ahora con la mitad de los miembros superando en algún punto el umbral de aviso naranja de más de $100 \mathrm{~mm}$ en 12 horas, pero sin despegarnos de una significativa incertidumbre espacial. Tenemos ya muy clara la probable formación de un SCM asociado a posibles precipitaciones copiosas. Como faltan dos días y, con nuestra debida cautela, ponemos un aviso naranja con probabilidad baja (10-40\%). Como persisten máximos previstos de 180-300 mm, dejamos la decisión para el día siguiente, con las próximas pasadas del RA $\gamma \mathrm{S}$, de aumentar la probabilidad del aviso naranja a moderada (40-70\%) o incluso de poner un aviso rojo.

4. Advertimos que hemos llegado a la madurez del episodio y del SCM y que nos disminuye significativamente la incertidumbre espacial (incertidumbre entre distintos miembros), consecuentemente aumentando las probabilidades en los ploteos. Prestamos además una especial atención a que los máximos de precipitación se disparan con zonas de 300-400 mm de lluvia acumulada e incluso se superan en dos localizaciones del litoral norte de Alicante los $400 \mathrm{~mm}$. Tomamos la decisión de poner, pues, un aviso naranja probable (40-70\%), pero lo localizamos solo en tres zonas. Se deja con preocupación y precaución para el día siguiente, esperando nueva información del RAYS, la decisión de subir el aviso a rojo.

\section{CONCLUSIONES}

Si las estructuras de mayor escala en niveles medio-altos se predicen adecuadamente, incluso modelos de baja resolución (e.g. INM/LAM 1991) pueden reproducir con cierta exactitud las estructuras de niveles bajos (centro de bajas presiones y flujo alimentador) asociadas con precipitación extrema, siendo posible una indicación explícita de precipitación intensa, al menos cuando la orografía juega un papel en su generación. 
a)

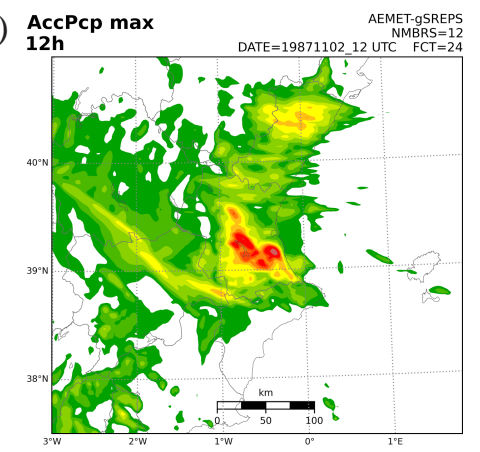

d) ${ }_{12 \mathrm{~h}}^{\text {AccPcp max }}$

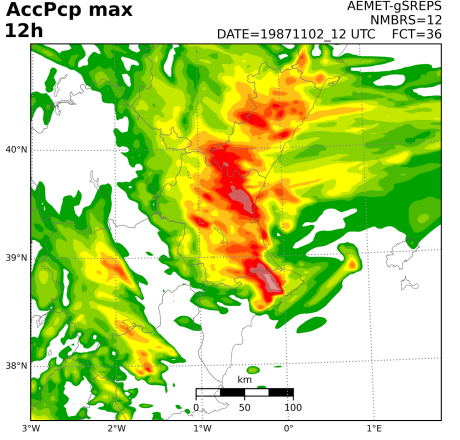

g) $\underset{12 h}{\text { AccPcp max }}$

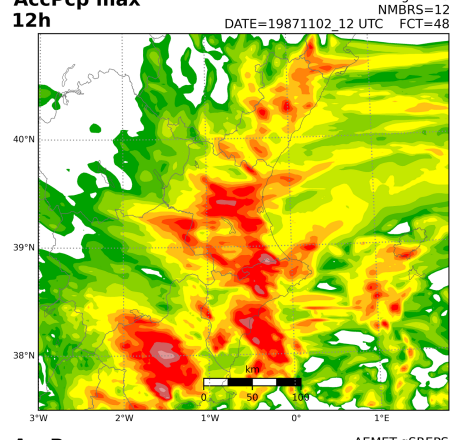

j) AccPcp max

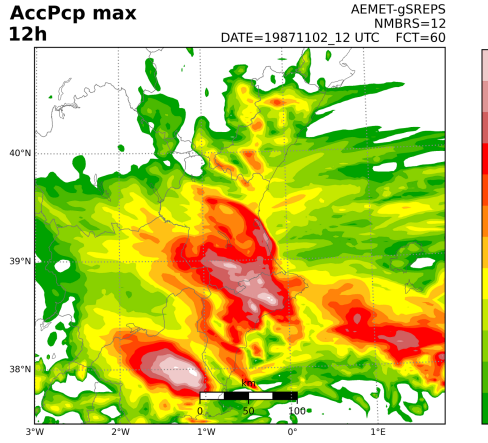

b)

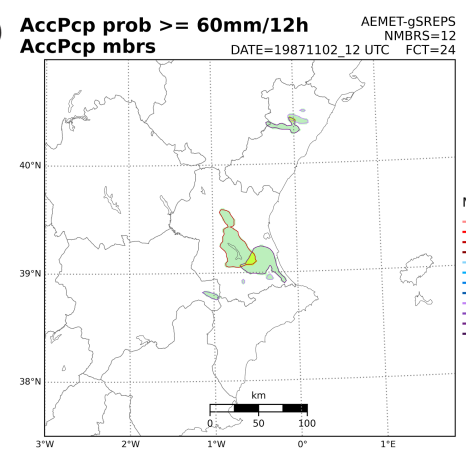

e) AccPcp prob $>=60 \mathrm{~mm} / \mathbf{1 2 h} \quad \begin{gathered}\text { AEMET-GSERS } \\ \text { NMBRS }=12\end{gathered}$
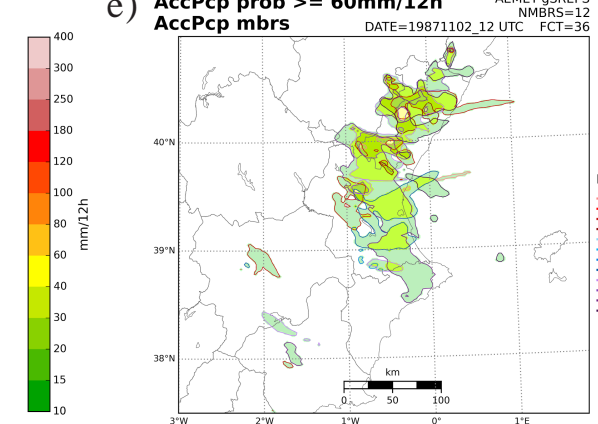

h)
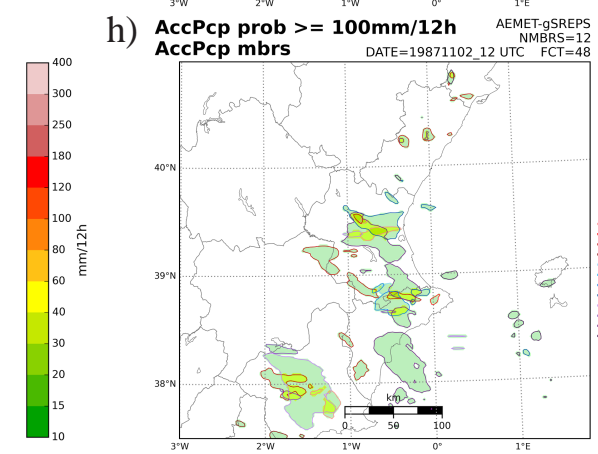

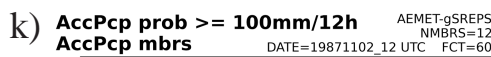

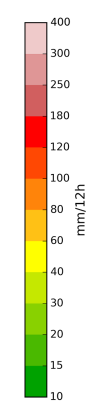

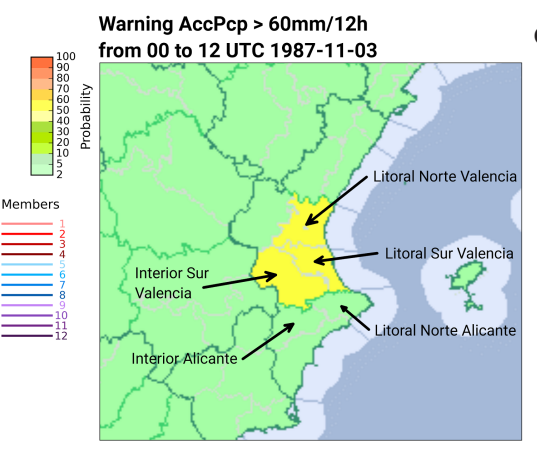

Warning AccPcp $>60 \mathrm{~mm} / 12 \mathrm{~h}$

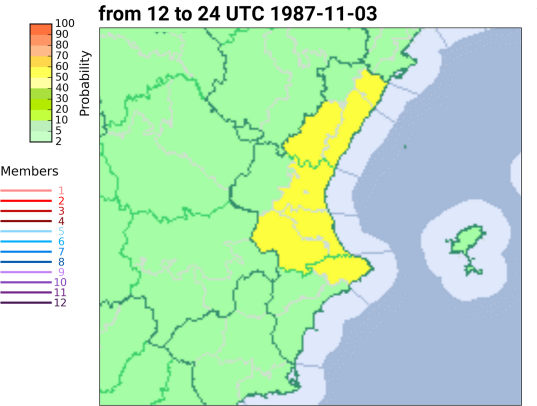

Warning AccPcp $>60 \mathrm{~mm} / 12 \mathrm{~h}$ and $100 \mathrm{~mm} / 12 \mathrm{~h}$ i)

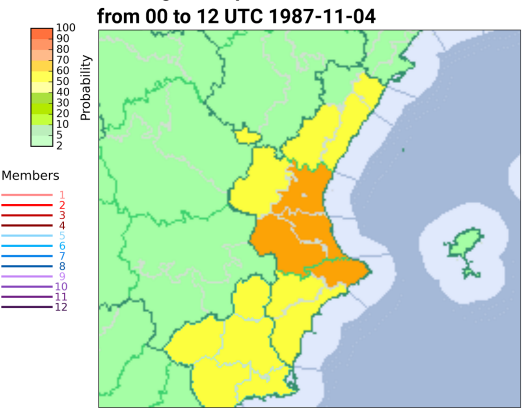

Warning AccPcp $<60 \mathrm{~mm} / 12 \mathrm{~h}$ and $100 \mathrm{~mm} / 12 \mathrm{~h} \quad$ ) from 12 to 24 UTC 1987-11-04

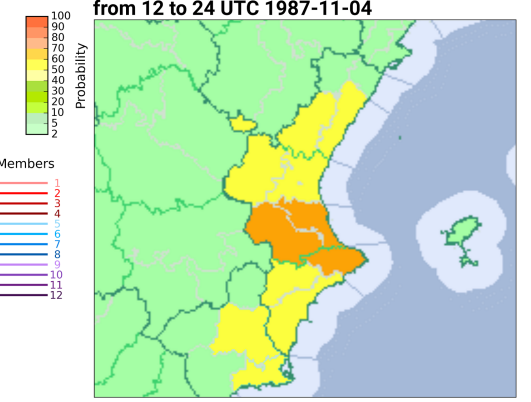

c)

Figura 13. Utilidad potencial de AEMET- $\gamma$ SREPS para la toma de decisiones en la emisión de avisos meteorológicos por precipitaciones intensas (véase texto).

Modelos de mesoescala no hidrostáticos actuales con mayor resolución (HARMONIE-AROME) brindan cantidades de precipitación más realistas, aunque no predicen todos los núcleos de precipitación extrema: en el caso de Oliva-Gandía, HARMONIE-AROME prevé el orográfico mucho mejor que el costero.

Un sistema de predicción por conjuntos (SPC) de mesoescala como AEMET- $\gamma$ SREPS puede ayudar dando una indicación aproximada de probabilidades de un evento de precipitación extrema, aunque los detalles no se perfilan de forma determinista. El núcleo orográfico vuelve a predecirse mejor, aunque esta vez sí que hay indicación del costero. 


\section{AGRADECIMIENTOS}

Damos nuestro sincero reconocimiento a Alejandro Roa Alonso por la organización y realización, contra viento y marea, del Sexto Simposio Nacional de Predicción. Este tipo de dinámicas se hacen imprescindibles si queremos que AEMET siga siendo una institución sin graves carencias. Por la edición del libro correspondiente, agradecemos a Miguel Ángel García Couto y todo el personal de la Biblioteca de AEMET. Agradecemos la buenísima disposición para facilitar algunas de las fotografías mostradas a Juan Ramón Porta del Excmo. Ayuntamiento de Oliva. De la Universidad de Illes Ballears (UIB) contribuyeron Víctor Homar, Romualdo Romero y Clemente Ramis. Agradecemos las contribuciones del personal de AEMET de la DT en Islas Baleares: Joan Campins, María Ángeles Picornell y José Antonio Guijarro.

Este artículo debe una parte de su existencia a los proyectos PREDIMED CGL2011-24458 (UIB, Ministerio de Ciencia e Innovación) y COASTEPS CGL201782868-R (UIB, MINECO/AEI/FEDER, UE) en los que participamos.

\section{REFERENCIAS}

ARmengot, R., 2002. Las lluvias intensas en la Comunidad Valenciana. Ministerio de MedioAmbiente, Madrid.

Bengtsson, L. et al., 2017. The HARMONIE-AROME Model Configuration in the ALADIN-HIRLAM NWP System. Monthly Weather Review, 145.5, pp. 1919-1935. doi: 10.1175/MWR-D-16-0417.1.

BurRIDGe, D. M. y HASELER, J., 1979. A semi-implicit global gridpoint model. Tech. Rep., ECMWF, Reading, England.

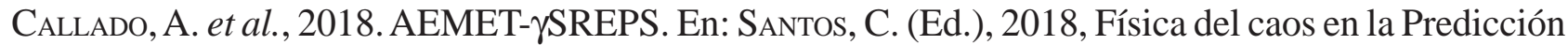
meteorológica. AEMET. pp. 333-360. doi: 10.31978/014-18-009-X.22.

Carreras, F. y Sarthou, C., 1910. Geografía general del Reino de Valencia. Volumen 1. A. Martín.

Cueva, A. J., 1994. Atlas climàtic de la Comunitat Valenciana, 1961-1990. Generalitat Valenciana, Conselleria d'Obres Públiques, Urbanisme i Transports.

DEE, D. P. et al., 2011. The ERA-Interim reanalysis: Configuration and performance of the data assimilation system. Quarterly Journal of the royal meteorological society, 137.656, pp. 553-597.

EBERT, E., 2001. Ability of a Poor Man's Ensemble to Predict the Probability and Distribution of Precipitation. Monthly Weather Review, 129.10, pp. 2461-2480. doi: 10.1175/1520-0493(2001)129<2461: AOAPMS>2.0.CO;2.

Grell, G. A.; DudhiA, J.; STAufFer, D. R. et al., 1994. A description of the fifth-generation Penn State/NCAR mesos-cale model (MM5). NCAR.

Gutiérrez, D. y Ghelli, A., 2018. El Centro Europeo de Predicción a Medio Plazo. En: Santos, C. (Ed.), 2018, Física del caos en la Predicción meteorológica. AEMET. pp. 289-300. doi: 10.31978/014-18-009-X.19.

Jansà, A.; García-Moya, J.A. y RodríGuez, E., 1991. Numerical experiments on heavy rain and Mediterranean cyclones. WMO/TD, 420, 37-47.

Jansà, A.; Armengot, R.; Simarro, J. P.; Callado, A.; Compte, M., 2018. Superrécord de Oliva-Gandía de 3-4 de noviembre de 1987. En: SAntos, C. (Ed.), 2018, Física del caos en la Predicción meteorológica. AEMET. pp. 655-688. doi: 10.31978/014-18-009-X.44. 
NúÑEZ, J. A., 2007. La riada de 1957 en Jávea. Análisis meteorológico y climático. En: L’aiguat de 1957. Ajuntament de Xàbia, 2007.

Quiby, J. y DeNHARD, M., 2003. SRNWP-DWD poor-man ensemble prediction system: the PEPS project. Eumetnet Newsletter, 8, pp. 9-12.

Riosalido, R.; Rivera, A. y Martín, F., 1988. Development of a mesoscale convective system in the Spanish Mediterranean Area. En: Proc. 7th Meteosat Scientific Users' Meeting, Madrid (pp. 27-30).

Romero, R. et al., 2000. Mesoscale Numerical Study of Two Cases of Long-Lived Quasi-Stationary Convective Systems over Eastern Spain. Monthly Weather Review, 128.11, pp. 3731-3751. doi: 10.1175/ 1520-0493(2001)129<3731:MNSOTC>2.0.CO;2.

RuIZ, J. A. y NúÑEZ, J. A., 2011. Sobre los periodos de retorno de las precipitaciones extraordinarias en la Comunidad Valenciana. Nota técnica. AEMET.

SAnTos (Ed.), 2018. Física del caos en la Predicción meteorológica. AEMET. 1184 pp. doi: 10.31978/01418-009-X.

UpPALA, S. M. et al., 2005. The ERA-40 reanalysis. Quarterly Journal of the royal meteorological society, 131.612 (2005), pp. 2961-3012. doi: 10.1256/qj.04.176.

WILKS, D. S., 2011. Statistical Methods in the Atmospheric Sciences. Academic Press. ISBN: 9780123850225. url: https://www.sciencedirect.com/bookseries/international-geophysics/vol/100. 
